\title{
Motivation is an Adjuvant Therapy for Pediatric Patients with Minimal Change Disease
}

\section{Mohamed Abdelaziz El-Gamasy}

Department of Pediatrics, Faculty of Medicine, Tanta University, Egypt

*Corresponding author: Mohamed Abdelaziz El-Gamasy, Department of Pediatrics, Faculty of Medicine, Tanta University, Egypt, Tel: 201208136076; E-mail: mgamsy@gmail.com

Received date: November 03, 2017, Accepted date: November 06, 2017, Published date: November 10, 2017

Copyright: (C) 2017 El-Gamasy MA. This is an open-access article distributed under the terms of the Creative Commons Attribution License, which permits unrestricted use, distribution, and reproduction in any medium, provided the original author and source are credited.

\begin{abstract}
Objectives: There were few publications which concern psychosocial motivation in pediatric patients with idiopathic nephritic syndrome(INS) to evaluated effects of psychological and social motivation on responsiveness of children with INS to steroid therapy and to detect whether there was relation between psychosocial motivation and the outcome of those children.
\end{abstract}

Subjects: This work was conducted as a randomized controlled clinical trial, single blinded study in Tanta university pediatric nephrology outpatient clinic on 172 children with Steroid Sensitive Nephrotic Syndrome (SSNS). They were divided randomly into motivational nephrotic group as Group 1 and a control nephrotic group as Group 2. Their aged 2-10 years and mean disease duration $2.6 \pm 2.1$ and $2.3 \pm 2.1$ years in Group 1 and 2 respectively.

Methods: Data was collected through a collection of biological, social and psychological data which were formulated, structured for 6 months where their ideas and expectations about disease, the compliance with treatment and follow up visits and frequency of relapses between the two studied patients groups were compared.

Results: There was statistically significant decrease in the number of relapses in Group 1 when compared to Group 2. Regarding compliance with follow up visits, there was a highly significant increase in Group 1 compared to control group. There was statistically significant difference after application of psychosocial motivation regarding patients' ideas and expectations about the disease.

Conclusions: The psychosocial motivation is significantly highly effective in improving the management of SSNS children, so we recommend all physicians to adopt psychosocial motivation to their nephritic children.

Keywords: Psychosocial motivation; Adjuvant therapy; Steroid sensitive nephrotic

\section{Introduction}

Nephrotic syndrome (NS) was classically defined as massive proteinuria $\left(>40 \mathrm{mg} / \mathrm{m}^{2} / \mathrm{hr}\right)$, hypoalbuminemia $(<2.5 \mathrm{gm} / \mathrm{dL})$, generalized edema, and hyperlipidemia in most of patients [1]. Its incidence was estimated as two to seven patients per one hundred thousand children per year and its prevalence was sixteen per one hundred thousands of patients below the age of 16 years [2]. Psychological manifestations of nephrotic children may be presented as depression, hyperactivity, or aggression. Social maladjustment might complicate nephritic patients in form of social withdrawal and or poor school achievement [3]. $80-90 \%$ of pediatric children with INS have SSNS, with a very good prognosis meaning complete recovery in most of patients. Unfortunately, SSNS usually have a remission and relapse sequlae. As a chronic disease, NS affects quality of life of affected patients especially in children and adolescents who have continues physical, behavioural social, emotional and intellectual growing development. It was recognized that NS could cause short- and longterm complications on physical, behavioural and psychosocial morbidities, particularly in those severely affected with frequent relapses, steroid dependence or steroid resistance [4]. Nephrotic relapses seemed to be precipitated by infections, especially upper respiratory tract infections, psychosocial stress like school examinations and stressful domestic events [5]. It was believed that psychological and social motivations have important impacts on the management of some organic diseases such as INS as it could differentiate between the actual pathophysiological mechanisms that cause the disease, and the child's and or his caregiver's perception of their illness and impacts of this illness on his general health. This concept was in contrast to the traditional concept of biology of medicine which stated that every disease process could be attributed to the presence of an aetiological factor that causes deviation from normal physiology such as a causative organism, inherited or acquired developmental abnormality, or injurious trauma [6]. The psychosocial motivations had marked significance to the disease; so the general pediatrician should be skilled to collect adequate data during their consultation by parents of kids. As well as taking detailed history about analysis of complaints in the present history including the signs symptoms and signs, general pediatrician should focus also on the patient's affective, beliefs, thoughts about the diseases, and should focus also on social factors such as the relationship of patient with families and the larger community (KG or school colleagues) aiming to improve his health outcome and to relieve the patient psychosocial burden of disease [7]. 
Page 2 of 7

The aim of this work was to assess whether psychosocial motivation for children with minimal change disease (MCD) can be used as adjuvant therapeutic modality to improve responsiveness to steroid therapy thus improving outcome of those children.

\section{Patients and Methods}

\section{Design and setting}

This study was randomized controlled clinical trial- single blinded study carried out in the period from October 2016 to October 2017 after approval from the research ethical committee of the Faculty of Medicine of Tanta University and informed written or verbal consents from parents of included patients.

\section{Sample size and sampling}

The sample size was calculated taking in consideration a significance level of $95 \%$, power $80 \%$ and effect size $30 \%$ resulting in 172 children to be selected then they were randomly subdivided into 2 groups, Group 1 included 86 known cases of MCD under psychosocial motivational therapy for 6 visits and Group 2 included 86 known cases of MCD without psychosocial motivational therapy.

Their ages ranged from 2-10 years who were selected from outpatient clinic and inpatient wards of Pediatric Nephrology Unit of Pediatric Department of Tanta University Hospital.

\section{Inclusion criteria}

All children of both sexes with INS who fulfilled responding to steroid therapy within 4 weeks of start of therapy. Both groups were managed by the routine protocol of management of nephrotic syndrome.

\section{Exclusion criteria}

Children less than 2 years of age, as they mostly could not SSNS or NS secondary to system ic diseases.

\section{Methods}

All patients were subjected to: Full history taking included personal data (name, age, sex, address, telephone,) history of diseases or developmental disorders, socioeconomic level, age of 1st presentation, duration of disease and subtype of steroid sensitive nephrotic syndrome which were:

- Frequent relapsing nephrotic syndrome which was defined as relapse $\geq 4$ times per year or $\geq 2$ times per 6 months. Relapse was defined as recurrence of proteinuria [urine albumin dipstick $\geq$ $2+$ on 3 consecutive days, most often in association with recurrence of edema

- Infrequent relapsing nephrotic syndrome: which was defined as relapse $<4$ times per year or $<2$ times per 6 months.

- Steroid dependent nephrotic syndrome which was defined as relapse every time with the withdrawal of steroids from every day to every other day therapy [8].

Thorough clinical examination included anthropometric measurements for assessment of nutritional status which included weight, height, Body mass index (BMI), Mid Arm Circumference (MAC) and vital signs especially arterial blood pressure which was measured by auscultatory method using a mercury sphygmomanometer, in the semi setting position after 10 minutes of rest, using an appropriate sized cuff and was taken as the mean value of 3 successive readings in 3 different days, presence of edema or presence of any complication either of the disease or for immunosuppressant agents used for treatment (e.g. Prednisolone, Cyclosporin A, Sandomun, Mycophenolate moefetyl or others)

Routine laboratory investigations (in the 1st visit only) including Boiling test for urine sample, complete urine analysis, 24 hour urinary proteins, complete blood count (CBC), erythrocyte sedimentation rate(ESR), serum albumin, total serum cholesterol and kidney function tests(BUN, serum creatinne).

Psychological assessment for evaluation of the ideas and expectations of pediatric patients or their caregivers about the disease using the modified childhood form of Illness perception questionnaire [9]. The questionnaires were filled through an interview with the child and the Caregiver, the questions were asked in lay language to the child if he was older than 6 years and to the caregiver if the child was $\leq 6$ years.

\section{Validity and reliability of used questionnaire}

A pilot study conducted on 17 patients with SSNS who were then excluded from our sample aiming to identify some items in the questionnaire which needed modifications before its application to our actual sample size. Modifications have been already done. The reliability of our questionnaire was 0.79 by cronbach's alpha Test. We conducted an interview with the patient and or his/her caregiver aiming a personalized health education to the studied patients and/or their caregivers for Group 1 only in the form of message which was constructed depending on the concept of psychosocial motivation including a general knowledge about nephrotic syndrome meaning its definition, causes, symptoms, signs, complications and how to deal with, triggers of relapse and how to avoid, stressing on the importance of adherence to management protocol and follow up visits, adequate nutrition, Self-protection against infections specially URTI, avoidance of stressful conditions and methods to reduce them and the importance of psychological and family support to the patients.

Disease outcome evaluation was measured by follow up visits after 6 months of the psychosocial motivational intervention for the 2 groups to compare between ideas and expectations about the disease and their compliance with treatment.

Good compliance with treatment was assessed if the patient ingests prednisolone tablets more than $80 \%$ of prescribed recommended doses [10], Good compliance with follow up were considered if the patient attended 5 or more out of 6 visits. Frequency of relapses was measured in both studied groups [8].

\section{Statistical Analysis}

Data was coded, entered and analyzed using SPSS program version 20 using chi square test, $\mathrm{t}$-test, and Mcnemar test. Cochran's $\mathrm{Q}$ test which is an extension to the McNemar test for related samples was used to test for differences between three or more matched sets of frequencies or proportions within each group. In each study group individuals are observed under different times. The data are coded as dichotomous variables containing 0 to represent failure (or absence of follow visit), and 1 to represent success (or its presence). Logistic regression analysis was done to control for confounders that could 
Page 3 of 7

affect the likelihood of relapses among the two study groups. The Odds of relapses in both study groups was calculated and Odds Ratio with $95 \%$ confidence interval with the relative estimate of risk. $\mathrm{P}$ value was set significant $\leq 0.05[11]$.

\section{Results}

Demographic data of the studied patients were summarized in Table 1. The age in studied Group 1 ranged between (2-10) years with a mean of $5.9 \pm 2.2$ while in Group 2, age ranged between (2-10) years with a mean of $5.9 \pm 2.3$.

Among 86 patients with Group 1, 56 (65.1\%) were males and 54 (62.8\%) were females and among 86 patients with Group 2, 54 (62.8\%) were males and $32(37.2 \%)$ were males with female: male ratio 1.87:1 and 1.69:1 in groups $1 \& 2$ respectively.

There was insignificant difference between studied patients and controls as regard age and sex (Table 1).

\begin{tabular}{|c|c|c|c|c|c|c|c|}
\hline \multicolumn{2}{|l|}{ Characteristics } & \multicolumn{2}{|c|}{ Motivated Group $(\mathrm{N}=86)$} & \multicolumn{2}{|c|}{ Control $(\mathrm{N}=86)$} & \multirow[t]{2}{*}{$\mathbf{X} 2$} & \multirow[t]{2}{*}{$P$ value } \\
\hline & & No & $\%$ & No & $\%$ & & \\
\hline \multirow[t]{2}{*}{ Gender } & Male & 56 & 65 & 54 & 63 & \multirow[t]{2}{*}{0.05} & \multirow[t]{2}{*}{0.8} \\
\hline & Female & 30 & 35 & 32 & 37 & & \\
\hline \multirow[t]{2}{*}{ Address } & Urban & 46 & 53 & 42 & 49 & \multirow[t]{2}{*}{0.2} & \multirow[t]{2}{*}{0.7} \\
\hline & Rural & 40 & 47 & 44 & 51 & & \\
\hline \multirow[t]{5}{*}{ Father education } & Illiterate & 42 & 49 & 40 & 47 & \multirow[t]{5}{*}{0.2} & \multirow[t]{5}{*}{0.9} \\
\hline & Read and write & 4 & 5 & 4 & 5 & & \\
\hline & Primary & 410 & 12 & 10 & 12 & & \\
\hline & Moderate & 24 & 28 & 24 & 28 & & \\
\hline & High & 6 & 8 & 8 & 9 & & \\
\hline \multirow[t]{5}{*}{ Mother education } & Illiterate & 28 & 33 & 30 & 35 & \multirow[t]{5}{*}{0.5} & \multirow[t]{5}{*}{1} \\
\hline & Read and write & 10 & 12 & 10 & 12 & & \\
\hline & Primary & 4 & 5 & 4 & 5 & & \\
\hline & Moderate & 42 & 49 & 38 & 44 & & \\
\hline & High & 2 & 23 & 4 & 5 & & \\
\hline \multirow[t]{5}{*}{ Father occupation } & Farmer & 12 & 14 & 14 & 16 & \multirow[t]{5}{*}{0} & \multirow[t]{5}{*}{1} \\
\hline & Worker & 40 & 46.5 & 40 & 46.5 & & \\
\hline & Skilled & 18 & 21 & 16 & 18.5 & & \\
\hline & Official & 12 & 14 & 12 & 14 & & \\
\hline & Professional & 4 & 5 & 4 & 5 & & \\
\hline \multirow[t]{2}{*}{ Mother occupation } & Not working & 80 & 93 & 80 & 93 & \multirow[t]{2}{*}{0} & \multirow[t]{2}{*}{1} \\
\hline & Working & 6 & 7 & 6 & 7 & & \\
\hline \multirow[t]{3}{*}{ Income } & Not enough & 30 & 35 & 32 & 37 & \multirow[t]{3}{*}{0.05} & \multirow[t]{3}{*}{0.97} \\
\hline & Enough & 46 & 35.5 & 44 & 51 & & \\
\hline & More than enough & 10 & 11.6 & 10 & 12 & & \\
\hline
\end{tabular}

Table 1: Demographic and social data of studied groups.

Table 2 shows that there were no statistically significant differences between the two studied groups as regard clinical characteristics at the beginning of the study $(\mathrm{p}>0.05)$.

The mean of disease duration was $2.58 \pm 2.08$ in Group 1 and $2.34 \pm$ 2.03 in Group 2. All clinical manifestations, clinical types, predisposing factors for relapse and complications of disease were statistically non significantly between the two studied patients groups ( $\mathrm{p}>0.05$ ).

Table 2 also shows that compliance with treatment of patients in the first group was statistically and significantly higher than those in the control group $(\mathrm{p}<0.05)$ (Table 2$)$. 
Citation: $\quad$ El-Gamasy MA (2017) Motivation is an Adjuvant Therapy for Pediatric Patients with Minimal Change Disease . J Gen Pract (Los Angel)

Page 4 of 7

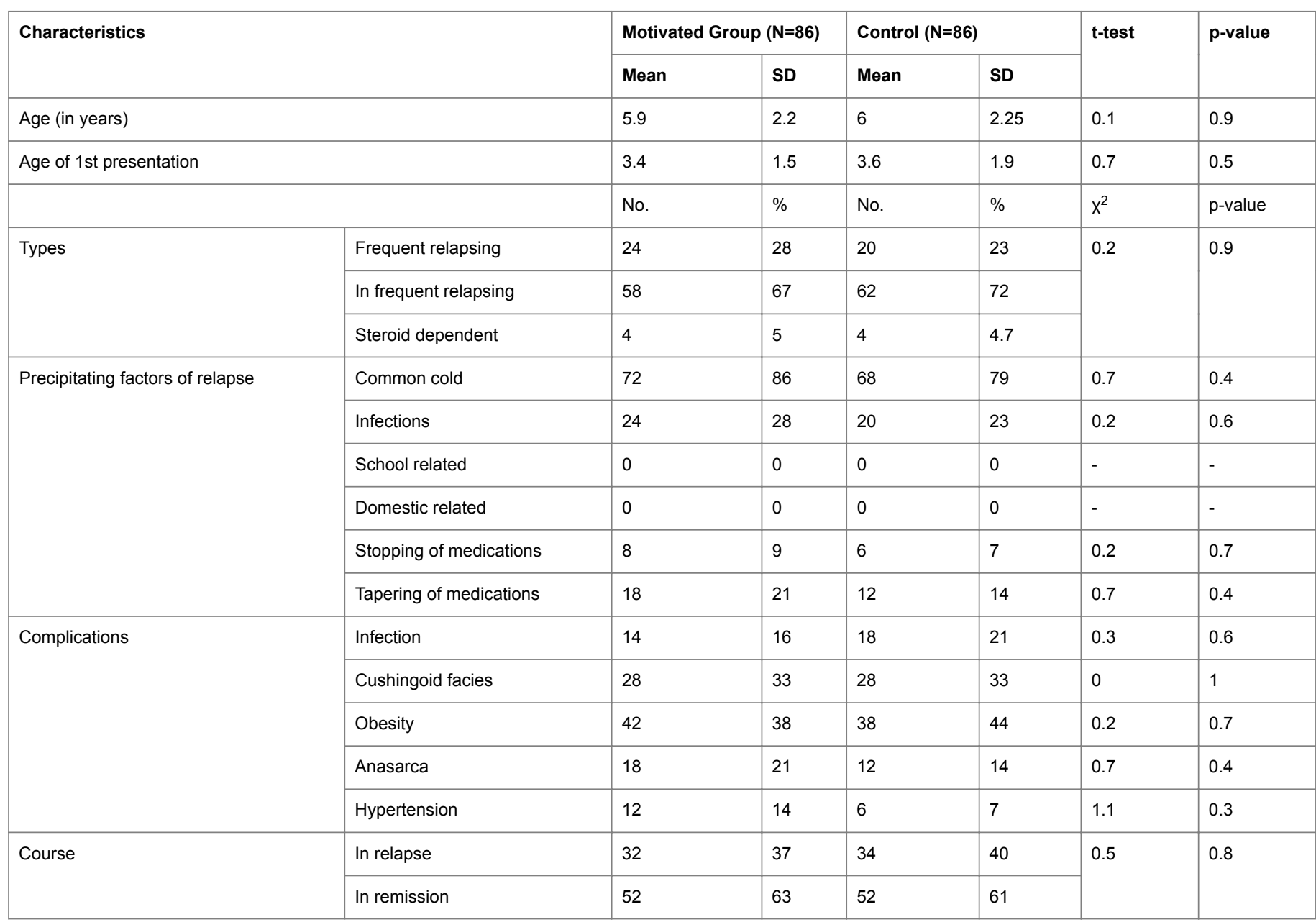

Table 2: Clinical data of studied groups.

Tables 3 and 4 shows that the baseline ideas and expectations of the patients or caregivers about the seriousness of disease, they were nearly the same with no significant difference before the application of psychosocial motivations ( $\mathrm{p}>0.05)$.
While there is highly statistically significant increase in number of the patients with ideas about the disease after psychosocial motivation in the first group in most of items when compared to control group $(\mathrm{p}<0.05)$ (Tables 3 and 4$)$.

\begin{tabular}{|c|c|c|c|c|c|c|c|c|c|c|}
\hline \multirow[t]{3}{*}{ Characteristics } & \multicolumn{3}{|c|}{ Motivated Group ( $\mathrm{N}=86$ ) } & & \multirow{2}{*}{\multicolumn{2}{|c|}{$\begin{array}{l}\text { Control }(\mathrm{N}=84) \\
\text { Before }(\mathrm{No}=84)\end{array}$}} & & & \multirow{3}{*}{$\begin{array}{l}\text { P-value } \\
\text { \#P3 }\end{array}$} & \multirow{3}{*}{ \#\#4 } \\
\hline & \multicolumn{2}{|c|}{ Before $(\mathrm{No}=84)$} & \multicolumn{2}{|c|}{ After $(\mathrm{N}=\mathbf{8 4})$} & & & \multicolumn{2}{|c|}{ After $(\mathrm{N}=\mathbf{8 4})$} & & \\
\hline & No & $\%$ & No & $\%$ & No & $\%$ & No & $\%$ & & \\
\hline \multirow[t]{2}{*}{ Serious disease } & 54 & 61 & 30 & 35 & 56 & 67 & 54 & 64 & 0.6 & 0.01 \\
\hline & \multicolumn{3}{|c|}{${ }^{*} \mathrm{P} 1=0.7$} & \multicolumn{4}{|c|}{${ }^{*} \mathrm{P} 2=0.1$} & & & \\
\hline \multirow[t]{2}{*}{ Has a big effect on life. } & 24 & 28 & 22 & 26 & 30 & 36 & 32 & 38 & 0.4 & 0.2 \\
\hline & \multicolumn{3}{|c|}{${ }^{*} \mathrm{P} 1=0.7$} & \multicolumn{4}{|c|}{${ }^{*} \mathrm{P} 2=0.1$} & & & \\
\hline \multirow[t]{2}{*}{ Others see the child differently } & 14 & 16 & 8 & 93 & 26 & 31 & 34 & 41 & 0.1 & 0 \\
\hline & \multicolumn{3}{|c|}{${ }^{*} \mathrm{P} 1=0.002$} & \multicolumn{4}{|c|}{${ }^{*} \mathrm{P} 2=0.1$} & & & \\
\hline Difficult for family and friends & 64 & 74 & 38 & 44 & 46 & 55 & 44 & 52 & 0.1 & 0.4 \\
\hline
\end{tabular}


Page 5 of 7

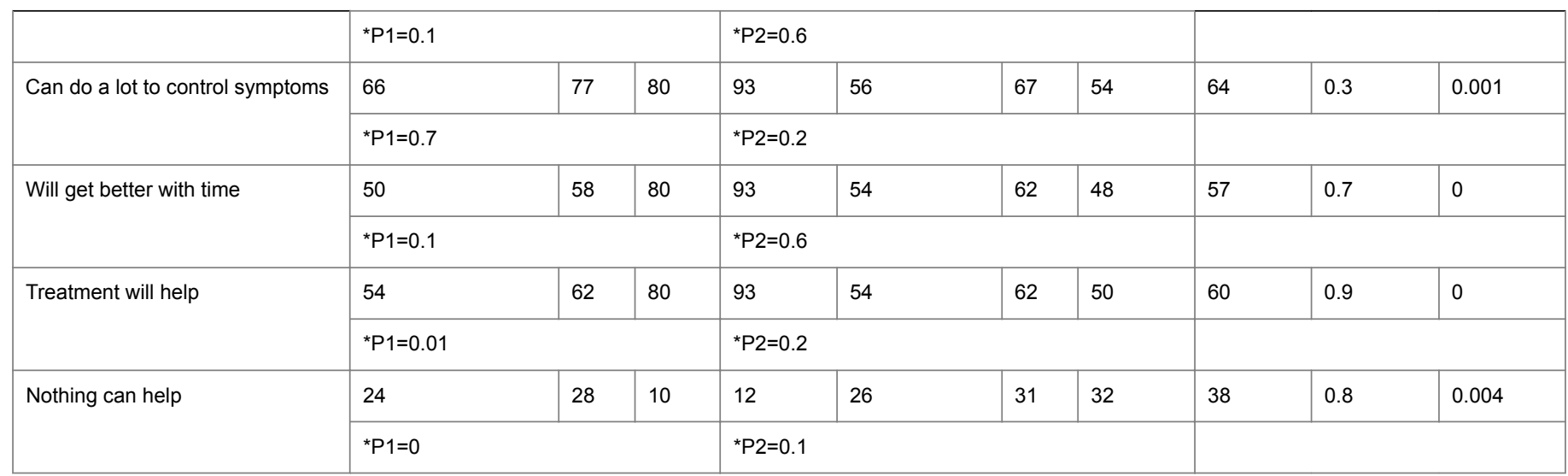

Table 3: Baseline idea, expectation and treatment compliance after 6 visits of studied groups.

\begin{tabular}{|l|l|l|l|l|l|}
\hline Characteristics & Motivated Group (N=86) & Control (N=86) & X2 \\
\hline & No & $\%$ & No & $\%$ & 55 \\
\hline Yes & 72 & 84 & 46 & 8 & 45 \\
\hline No & 14 & 16 & 38 & 0.01 \\
\hline
\end{tabular}

Table 4: Comparison between the studied groups as regard compliance with treatment for the six visits.

Figure 1 shows that the frequency of attendance at each scheduled visit (after the first one) was significantly higher in the first group ( $\mathrm{p} \leq$ 0.05 ) when compared to second group, and also showed that there was a significant increase in the proportions of patients who were compliant to follow up visits in the first group when compared to second group $(\mathrm{p}=0.04)$.

This was opposed by a non-significant change in compliance to follow up in hospital based model group $(\mathrm{p}=0.75)$ (Figure 1$)$.

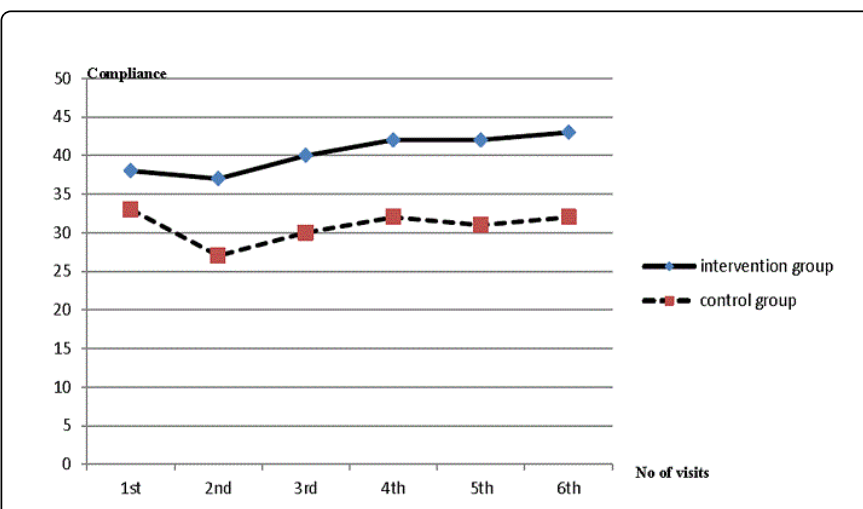

Figure 1: Compliance of the patients in motivated and control groups with the follow up visits.

Figure 2 shows a difference in frequency of relapses between studied patients groups varied from visit to visit with significant difference between the two groups at $6^{\text {th }}$ visit $(\mathrm{p}=0.02)$.
However, there was a significant decrease in the proportion of relapses from the first visit (16.3\%) to the sixth visit (no relapse at all) in the first group, $(\mathrm{p}=0.02)$ compared to non-significant drop in relapses in control group ( $\mathrm{p}=0.98$ ) (Figure 2$)$.

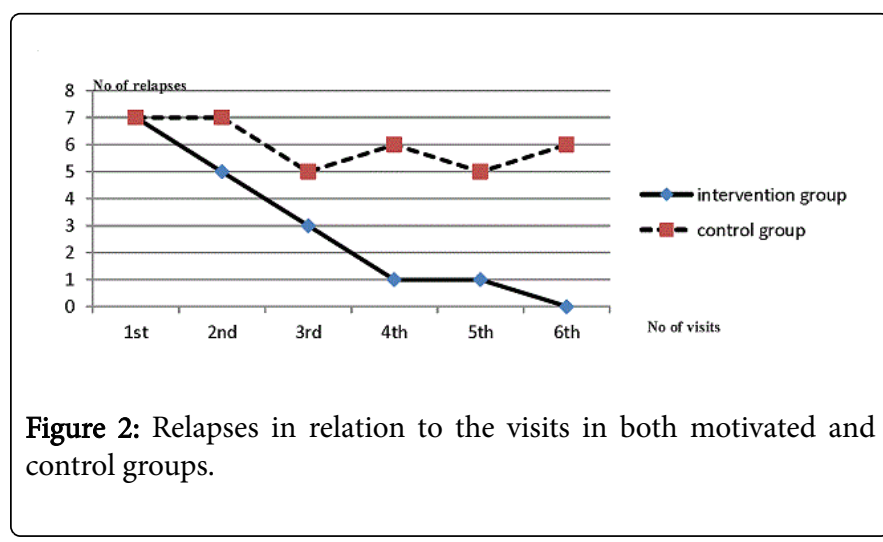

Table 5 shows multivariate logistic regression analysis in which the number of follow up visits as an independent variable significantly affects the occurrence of relapses.

When it was less than 5 visits during the six months of follow up, it increases the odds of relapse 7.4 times in children with NS compared to those with $>5$ visits with $95.0 \%$ C.I. of (2.5-22.3) (Table 5). 
Page 6 of 7

\begin{tabular}{|l|l|l|l|l|l|l|}
\hline Characteristics & B & SE & P value & Odds ratio (OR) & 95.0\% C.I. for OR \\
\cline { 3 - 7 } & & & & Lower & Upper \\
\hline Follow up visits $\leq 4$ & 2 & 0.6 & 0 & 7.4 & 2.5 & - \\
\hline Constant & -0.5 & 0.3 & 0.1 & 0.6 & - \\
\hline B=Regression coefficient, SE=Standard Error, p value is significant $\leq 0.05$ &
\end{tabular}

Table 5: Logistic regression analysis of relapse with number of follow-up visits.

\section{Discussion}

One of the most recent therapeutic modalities of pediatric nephrotic syndrome is to psychiatric support of the patient and or his or her caregiver in conducting essential self-care behaviour by encouragement them for performance of regular effective self-care behavioral therapy and educating patients in their appropriate application.

The efficacy of the psychosocial motivations may be attributed to the synchronizing effects of variable therapeutic factors including proper patient health education, adequate dietary regimen and psychological therapeutic interventions. On controlling these factors, a better control of INS can be easily achieved [7]. This work as a randomized controlled clinical trial-single blinded study was conducted in Tanta University pediatric nephrology outpatient clinic. In our study the effectiveness of Psychosocial motivations was calculated by the difference in the outcome of INS by measurement of occurrence and frequency of relapse of disease, patients compliance with treatment and patients compliance with follow up visits as well as improvement of emotional, behavioural or psychological complaints if present. The effect of the psychosocial motivations on the outcome of idiopathic nephrotic syndrome in pediatric age has been rarely evaluated owing to the latest available information on medical web sites.

Our results revealed non-significant difference between patients with SSNS under psychosocial motivation and control groups regarding their baseline data including sociodemographic characters, duration of disease and relapses which was also reflected on characters related to the disease. This was a good indicator for us about the effective randomization of patients between two groups.

On measuring compliance of patients with treatment and with follow up visits among our two groups there was a statistically significant difference between Group 1 and controls with high level of compliance $(83.7 \%)$ in the first group, while $(67.4 \%)$ came for 6 visits and this difference begins from 2 nd visit till 6 th one to reach $100 \%$ in the first group opposite to $76.2 \%$ in the control group. These results are similar to those of the study conducted in Colombia where the efficacy of a bio-psychosocial intervention program for hypertensive patients was measured, where the post-intervention changes in adherence to treatment were $(86.6 \%$ of the studied patients) which was also significantly different from non-intervention group $(p>0.05)$ [12]. This could be explained by the facts that health outcomes including adherence of patients to treatment were much improved when patients were involved in managing their own chronic illness [13], also it may be attributed to the effect of patient health education which was included in our intervention and which was directed toward the parents of involved kids as our results demonstrated that patients' ideas and expectations about the treatment of disease and its effects in improvement of the general healthy status of their children differed significantly after application of psychosocial model compared to the control group who didn't receive an health educational message based. This explanation was previously supported by other studies which were concluded that patient health education and or parents' health education as regard disease sequlae, aetiology, predisposing factors for relapse, medications, their benefits, and their potential side-effects could enhance patients' compliance, this was especially true in children with chronic diseases [14]. Also it was an indication for our study about the effective difference in application of health education based on psychosocial motivation therapy.

As regard relapses of INS in our studied patients, our results showed a statistically significant decrease in relapse rate in Group 1 when compared with control group especially in the 6th visit where relapses were absent in the first group in relation to its occurrence in $14.3 \%$ of the control group. This promising result could be attributed to the good compliance with treatment and better follow up of patients of Group 1 when compared to Group 2, So the nephrotic patients need beside drug therapy an educated helpful personnel that can enter their life and make important changes in their feelings, thinking, behaviours, lifestyle aiming better positive reaction against chronic disease like INS. Our results showed that increasing regular follow up visits was very effective with the nephrotic patients in the first group (who receive patient education beside the ordinary pharmacological therapy). This finding was supported by Delamater et al., who proved that the application of social and psychological interventions beside the biological treatment can improve the quality of life and can improve adherence of diabetic children to treatment regimen as an example of common chronic disease in pediatric age [15]. Limitations of this study included some patients' unresponsiveness, short consultation session time (around 15 minutes) and small sample sizes.

\section{Conclusion}

The psychosocial motivation is highly effective as adjuvant therapy in control of the pediatric patients with MCD as SSNS.

\section{Recommendations}

We recommend the application of the psychosocial motivation as adjuvant therapy for control of nephrotic children through training, better learning of general pediatricians about knowledge and skills of psychosocial motivational therapy.

\section{References}

1. Park S, Shin J (2011) Complications of nephrotic syndrome. Korean J Pediatr 54: 322-328. 
Citation: $\quad$ El-Gamasy MA (2017) Motivation is an Adjuvant Therapy for Pediatric Patients with Minimal Change Disease . J Gen Pract (Los Angel) 5: 338. doi:10.4172/2329-9126.1000338

Page 7 of 7

2. Mortazavi F, Khiavi Y (2011) Steroid response pattern and outcome of pediatric idiopathic nephrotic syndrome: A single-center experience in northwest Iran. Ther Clin Risk Manag 7: 167-171.

3. Guha P, Arun D, Ghosal M (2009) Behavior profile of children with nephrotic syndrome. Indian J Psychiatry 51: 122-126.

4. Mitra S, Banerjee S (2011) The impact of pediatric nephritic syndrome on families. Pediatr Nephrol 26: 1235-1240.

5. Takahashi SH, Wada N, Murakami H, Funaki S, Inagaki T, et al. (2006) Triggers of relapse in steroid-dependent and frequently relapsing nephrotic syndrome. Pediatr Nephrol 22: 232-236.

6. Brian RT, Nancy DK, Robert JG (2008) Biopsychosocial factors that perpetuate chronic pain, impairment, and disability. Psychol Inj Law 1: $182-190$.

7. Gatchel RJ, Turk DC, Dennis C (2008) Criticisms of the biopsychosocial model in spine care: Creating and then attacking a straw person. Spine Update 33: 2831-2836.

8. Niaudet P (2004) Steroid-sensitive idiopathic nephrotic syndrome. In: Avner ED, Harmon WE, Niaudet P (eds) Pediatric Nephrology. ( $5^{\text {th }}$ edn) Lippincott Williams and Wilkins, Philadelphia, USA, pp. 545-73.

9. Weinman J, Petrie KJ, Moss MR, Horne R (1996) The illness perception questionnaire: A new method for assessing the cognitive representation of illness. Psychol Health 11: 114-129.
10. Vermeire E, Hearnshaw H, Van Royen P, Denekens J (2001) Patient adherence to treatment: Three decades of research. A comprehensive review. J Clin Pharm Ther 26: 331-342.

11. Khothari CR (2012) Research methodology, methods and Techniques. ( $2^{\text {nd }}$ edn), New Age International, New Delhi, India, pp. 95-97.

12. Holguín L, Correa D, Arrivillaga M, Cáceres D, Varela M (2006) Treatment compliance in arterial hypertension: Efficacy a biopsychosocial intervention program. Univ Psychol 5: 535-548.

13. Bodenheimer T, Lorig K, Holman H, Grumbach K (2002) Patient selfmanagement of chronic disease in primary care. JAMA 288: 2469-2475.

14. Penkower L, Dew MA, Ellis D, Sereika SM, Kitutu JM, et al. (2003) Psychological distress and adherence to the medical regimen among adolescent. Am J Transplant 3: 112-118.

15. Delamater AM, Jacobson AM, Anderson B, Cox D, Fisher L, et al. (2001) Psychosocial therapies working group psychosocial therapies working group psychosocial therapies in diabetes: Report of the psychosocial therapies working group. Diabetes Care 24: 1286-1292. 